\title{
Thrombospondin- 2 inhibits tumor cell invasion through the modulation of MMP-9 and UPA in pancreatic cancer cells
}

\author{
MASATO NAKAMURA ${ }^{1,4,6}$, YASUHISA OIDA ${ }^{2,5}$, YOSHIYUKI ABE ${ }^{3,4}$, HITOSHI YAMAZAKI $^{4}$, \\ MASAYA MUKAI ${ }^{2}$, MASAHIRO MATSUYAMA ${ }^{5}$, TSUYOSHI CHIJIWA ${ }^{4}$, \\ HOZUMI MATSUMOTO ${ }^{4}$ and YOSHITO UEYAMA ${ }^{4,6}$
}

\author{
Departments of ${ }^{1}$ Pathology, and ${ }^{2}$ Surgery, Tokai University Hachioji Hospital, Ishikawa, Hachioji, \\ Tokyo 192-0032; ${ }^{3}$ Tokorozawa PET Diagnostic Imaging Clinic, Tokorozawa, Saitama 359-1124; Departments of \\ ${ }^{4}$ Pathology, and ${ }^{5}$ Surgery, Tokai University School of Medicine, Bohseidai, Isehara, Kanagawa 259-1193; \\ ${ }^{6} \mathrm{Central}$ Institute for Experimental Animals, Nogawa, Kawasaki, Kanagawa 216-0003, Japan
}

Received December 17, 2007; Accepted January 31, 2008

\begin{abstract}
The extracellular matrix protein thrombospondin (TSP) plays an important role in a variety of biological processes, including cell-cell and cell-matrix interactions. The biological role of TSP-2 in invasion and metastasis is poorly understood, while it is known that TSP-1 regulates a proteolytic cascade that allows tumor cells to invade and metastasize. In this study, we examined the role of TSP-2 in tumor cell invasion and its association with proteolytic proteins, matrix metalloproteinase (MMP) and the plasminogen/plasmin system, including urokinase-type plasminogen activator (uPA), in the human pancreatic cancer cell line PANC-1. PANC-1 cells expressed a low level of TSP-2, but significant levels of TSP-1. We isolated three clones of PANC-1 transformants stably overexpressing human TSP-2 (PANC-T). PANC-T highly expressed the TSP-2 gene and protein, while TSP-1 expression was not altered. In vitro invasion assays demonstrated that the invasiveness of PANC-T clones was significantly suppressed $(\mathrm{p}<0.05$; Welch test). Zymography revealed that restoration of TSP-2 synthesis in the PANC-T clones significantly inhibited MMP-9 activity $(\mathrm{p}<0.05$; Welch test). uPA activity in the PANC-T clones was significantly suppressed $(\mathrm{p}<0.05$; Welch test). We concluded that restoration of TSP-2 can inhibit cell invasion through the down-regulation of MMP-9 and uPA activity in pancreatic cancer cell lines. Thus, TSP-2 may be a potent inhibitor of metastasis in pancreatic cancer.
\end{abstract}

Correspondence to: Dr Masato Nakamura, Department of Pathology, Tokai University School of Medicine, Tokai University Hachioji Hospital, Ishikawa 1838, Hachioji city, Tokyo 192-0032, Japan E-mail: nakamura.masato@hachioji-hosp.tokai.ac.jp

Abbreviations: TSP, thrombospondin; MMP, matrix metalloproteinase; uPA, urokinase-type plasminogen activator

Key words: thrombospondin-2, pancreatic cancer, invasion, matrix metalloproteinase-9, urokinase-type plasminogen activator

\section{Introduction}

Pancreatic cancer is the fourth leading cause of cancer-related death in men and women in developed countries, and its incidence seems to be increasing (1). Despite advances in diagnosis and staging, the overall 5-year survival rate for patients diagnosed with this deadly cancer averages less than $1 \%$. Only $10 \%$ of pancreatic cancer patients have a localized disease amenable to surgical resection at the time of diagnosis. This has been explained by the difficulty of early detection of the neoplastic process, lack of effective treatment and limited knowledge of the specific biological features of pancreatic cancer (2).

Thrombospondin (TSP) is a family of glycoproteins and has at least five subtypes encoded by independent genes. Among the TSPs, TSP-1 and -2 contain three properdin-like type- 1 repeats (TSR), unlike other TSPs (3-8). Accumulating evidence suggests that TSP-1 functions as a modulator of tumor metastasis and angiogenesis, up-regulating tumor cell invasion through the modulation of matrix metalloproteinase (MMP)-9 and the plasminogen/plasmin system. Meanwhile, TSP-2 has recently attracted attention as an endogenous negative regulator of angiogenesis in tumorigenesis $(9,10)$. As it shows poor sequence homology to TSP-1 in the procollagen region, but good homology in the TSR region, it has been suggested that the anti-angiogenic activity of TSP-2 maps to the TSR region (11). There have been a number of reports concerning the biological activities of TSP-2. Murine and bovine TSP-2 protein inhibits the migration of bovine adrenal capillary endothelial cells and neovascularization induced in the rat cornea (3). In vivo tumor growth and the angiogenesis of human squamous cell carcinoma cell lines was inhibited by transfection with murine TSP-2 complementary DNA (cDNA) (4). Further functions and properties of TSP-2 with respect to tumor progression are not well understood compared to those of TSP-1 (12-14).

Invasion and metastasis are hallmarks of malignant tumors, and both involve multiple processes. Before they can invade tissues and metastasize, tumor cells must cross the extracellular matrix, which consists of combinations of proteinaceous fibers and carbohydrate macromolecules. Several classes of proteases 
may be involved in the proteolytic events which occur during tumor invasion (15). Of particular significance are the serine proteinases, such as urokinase-type plasminogen activator (uPA), and MMPs, especially MMP-9. The enzyme uPA converts the inactive proenzyme plasminogen into the potent general protease plasmin. Plasmin is now known to activate the precursors of MMPs, thereby greatly extending the range of susceptible substrates (16). In our previous report, human colon cancer cell lines transfected with human TSP- 2 cDNA showed down-regulation of MMP-2 and MMP-9 mRNAs $(17,18)$. These results suggest that TSP-2, as well as TSP-1, may play an important role as a potent inhibitor of tumor metastasis.

In this study, we isolated and transfected human TSP-2 cDNA into PANC-1, which expressed a low level of TSP-2 mRNA, and examined the role of TSP-2 in tumor cell invasion and the regulation of MMP-9 and UPA in pancreatic cancer.

\section{Materials and methods}

Cell lines. Human pancreatic cancer cell lines PANC-1 (poorlydifferentiated), MIA PaCa-2 (undifferentiated), Capan-2 (well-differentiated) and BxPC-3 (well-differentiated) were obtained from American Type Culture Collection (ATCC; Rockville, MD). PANC-1 and MIA PaCa-2 were cultured in DMEM supplemented with $10 \%$ fetal bovine serum, and Capan-2 and BxPC-3 were cultured in RPMI-1640 supplemented with $10 \%$ fetal bovine serum. All cell lines were maintained at $37^{\circ} \mathrm{C}$ in a humidified $5 \% \mathrm{CO}_{2}$ plus $95 \%$ air atmosphere.

Real-time polymerase chain reaction $(P C R)$. Total cellular RNA from pancreatic cancer cells was isolated by standard acid guanidine isothiocyanate-phenol-chloroform extraction procedures. After heat-denaturation of total RNA specimens $(1 \mu \mathrm{g})$, reverse transcription was performed using $10 \mathrm{mM}$ DTT, (Invitrogen Corp., Carlsbad, CA) 0.2 mM dNTPs (Toyobo Co., Osaka, Japan) 100 pmol of Primer, Random PD (N6) (Roche Diagnostics Co., Hague Road, Indianapolis, IN) and $200 \mathrm{U}$ of Superscript ${ }^{\mathrm{TM}}$ II RNase $\mathrm{H}^{-}$Reverse Transcriptase (Invitrogen) at $42^{\circ} \mathrm{C}$ for $60 \mathrm{~min}(19,20)$. Real-time quantitative PCR for TSP-1 and -2 was performed as previously described (21). B-actin-probe-primer mix (PE Applied Biosystems) was used as an internal control.

Transfection of human TSP-2 cDNA. The human TSP-2 cDNA expression vector was previously constructed in our laboratory. PANC-1 cells were transfected with the human TSP-2 expression plasmid or vector alone plasmid, using Lipofectin ${ }^{\circledR}$ Reagent (Invitrogen) according to the manufacturer's recommendations. Stable transfectants were selected with $600 \mu \mathrm{g} / \mathrm{ml}$ G418 for 4-8 weeks, and resistant clones were isolated and used for experiments.

Cell viability. Cells were seeded at $1 \times 10^{4}$ cells/well in 6-well plates. Cell number was determined by trypan blue exclusion with a hemacytometer at 5 time points over $96 \mathrm{~h}$. Triplicate cultures of each cell line were prepared at all time points.

Western blot analysis. Western blot analysis was performed to examine TSP-2 protein secretion in conditioned media as

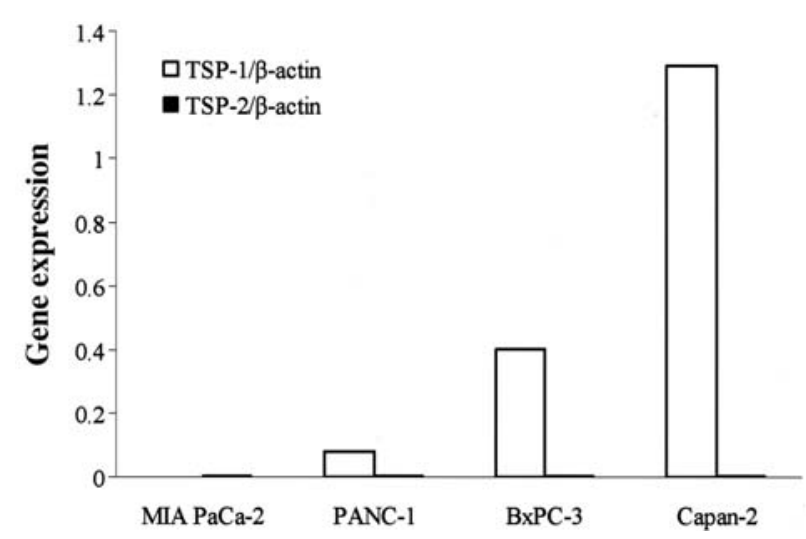

Figure 1. Constitutive expression of TSP-1 and -2 in human pancreatic cancer cell lines. The gene expression in four pancreatic cancer cell lines, MIA PaCa-2, PANC-1, BxPC-3 and Capan-2, was examined by quantitative realtime PCR. TSP-1 mRNA were strongly expressed by Capan-2, but were observed at low levels in MIA PaCa-2, PANC-1 and BxPC-3. A low level or no expression of TSP-2 mRNA was detected in all four cell lines.

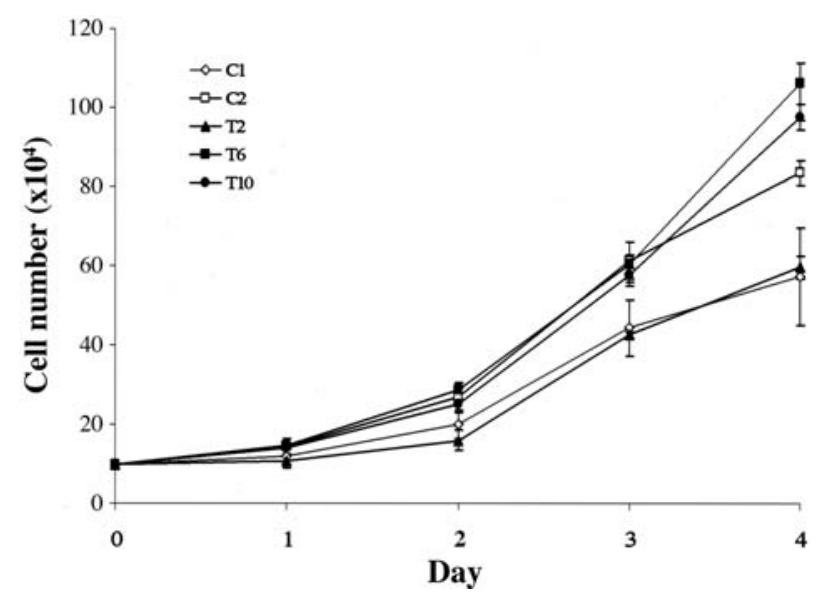

Figure 2. Cell growth of PANC-1 cells transfected with vector only (PANC-C) or human TSP-2 expression vector (PANC-T). No significant difference in cell growth between PANC-C cells (C1 and C2) and PANC-T cells (T2, T6 and T10) was observed over a $96-\mathrm{h}$ period.

previously described (22). Briefly, samples of conditioned media were boiled in denaturing sample buffer and fractionated by electrophoresis on $10 \%$ sodium dodecyl sulfate (SDS)-polyacrylamide gels, then transferred to nitrocellulose membranes (ECL membrane; Amersham Pharmacia Biotech, Buckinghamshire, UK). The following primary antibodies were used for detection: TSP-1 and -2 (Santa Cruz Biotechnology Inc., Santa Cruz, CA). The proteins were detected using appropriate horseradish peroxidase-conjugated secondary antibodies and visualized on enhanced chemiluminescence film (Hyperfilm; Amersham) by application of Amersham's Enhanced Chemiluminescence Western Blotting Detection System.

Tumor cell invasion assay. Invasion was assayed in BD BioCoat $^{\mathrm{TM}}$ Matrigel $^{\mathrm{TM}}$ Invasion Chambers (24-well, 8- $\mu \mathrm{m}$ pore, Becton-Dickinson Labware, Bedford, MA). Control insert chambers were used for the migration assay. DMEM supplemented with 5\% FBS was used as a chemoattractant. Cells $\left(2.5 \times 10^{3}\right)$ were suspended in serum-free DMEM and seeded onto invasion chambers and control chambers. After $24 \mathrm{~h}$ of incubation, cells were fixed with methanol and stained 
with crystal violet for $15 \mathrm{~min}$. Cells remaining on the upper face of the membranes were scraped and those on the lower face were counted using an inverted microscope. All assays were performed in triplicate. The counting was performed for 3 fields in each sample and the experiment was conducted 3 times. Cellular invasiveness was normalized to the number of cells that had migrated through the Matrigel.

Zymography. The expression of MMP-9 in conditioned media was analyzed by gelatin zymography (23). The conditioned media of each type of cell were mixed with sample buffer (4.5\% SDS, 0.125 M Tris- $\mathrm{HCl}, 22 \%$ glycerol, $0.01 \%$ bromophenol blue). Electrophoresis was carried out on $0.1 \%$ SDS $10 \%$ polyacrylamide gels containing $1 \mathrm{mg} / \mathrm{ml}$ of gelatin. Following electrophoresis, the gel was rinsed twice with renaturing buffer (2.5\% Triton $\mathrm{X}-100 / 50 \mathrm{mM}$ Tris-HCl, $\mathrm{pH} 7.4)$ and incubated at $37^{\circ} \mathrm{C}$ for $16 \mathrm{~h}$ in developing buffer $(150 \mathrm{mM} \mathrm{NaCl} /$ $10 \mathrm{mM} \mathrm{CaCl}_{2} / 0.05 \% \mathrm{NaN}_{3} / 50 \mathrm{mM}$ Tris- $\mathrm{HCl}, \mathrm{pH}$ 7.4). White lysis zones in gelatin zymography indicated degrading activity.

Enzyme-linked immunosorbent assay (ELISA). The uPA concentration in conditioned media was measured using an Imubind Total uPA ELISA Kit (American Diagnostica Inc., Greenwich, CT). The lower limit of detection of the assays was $0.1 \mathrm{ng}$ total uPA ml/sample. Assay procedures were performed according to the vendor's instructions. Results shown are the average of three separate determinations.

Statistical analysis. Statistical comparisons of data sets to the control (PANC-C) were performed by the 2-sample t-test for inequality distribution (Welch test). Data are shown as the means \pm standard error of mean (SEM). The analyses were performed using JMP version 5 software (SAS Institute Inc., Cary, NC). p-values $<0.05$ were considered statistically significant.

\section{Results}

Constitutive expression of TSP-1 and -2 in human pancreatic cancer cell lines. The expression of TSP-1 and - 2 mRNA was examined in four human pancreatic cancer cell lines by quantitative real-time PCR. Capan-2, PANC-1 and BxPC-3 expressed TSP-1 mRNA, but little expression was observed in MIA PaCa-2 (Fig. 1). Meanwhile, very low levels or no expression of TSP-2 mRNA were detected in all four cell lines. The protein levels of secreted TSP-1 and -2 were also confirmed by Western blot analysis (data not shown), and the protein levels in each pancreatic cancer cell line reflected the respective mRNA levels.

Expression of TSP-1 and -2 in TSP-2-transfected PANC-1 (PANC-T) cells. We transfected TSP-2 cDNA into the human pancreatic cell line PANC-1 and established TSP-2-overexpressing clones (PANC-T). There was no significant difference in cell growth among three such clones derived from PANC-T (T2, T6 and T10) (Fig. 2). The gene expression levels of TSP-2 in these clones were confirmed by real-time RT-PCR. None of these clones showed marked expression of TSP-1, while all three TSP-2-transfectants (T2, T6 and T10) showed significantly stronger expression of TSP-2 mRNA (T2, $\left.0.36 \pm 0.59 \times 10^{-1} ; \mathrm{T} 6,0.59 \pm 0.17 \times 10^{-2} ; \mathrm{T} 10,0.18 \pm 0.23 \times 10^{-1}\right)$ than
$\mathbf{A}$

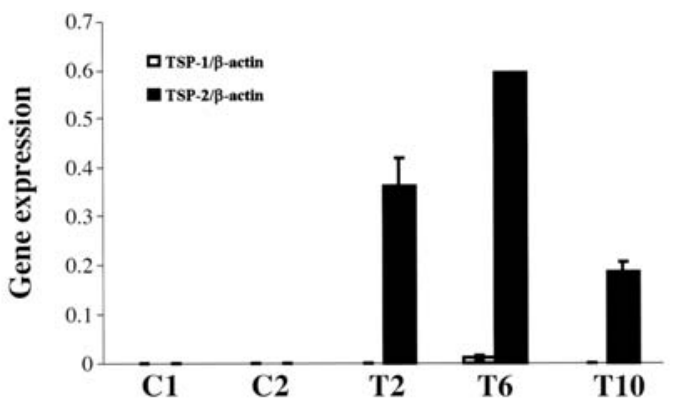

B

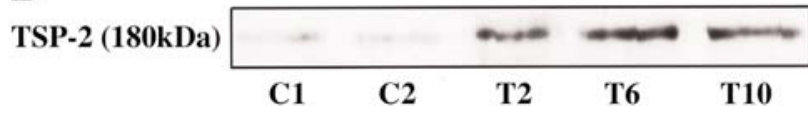

Figure 3. Expression of TSP-1 and -2 in PANC-1 clones stably transfected with TSP-2. Gene expression in PANC-C cells (C1 and C2) and PANC-T cells (T2, T6 and T10) was examined by quantitative real-time PCR. (A) Little or no TSP-2 mRNA expression was detected in either PANC-C or -T clones. Overexpression of TSP-2 mRNA was confirmed in PANC-T clones, but almost no expression of TSP-2 mRNA was observed. (B) Western blot analysis of conditioned media also confirmed high levels of TSP-2 secretion in PANC-T clones and no TSP-2 secretion in PANC-C clones.

A

B

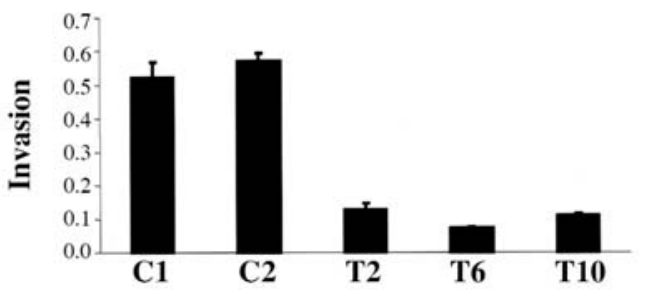

C
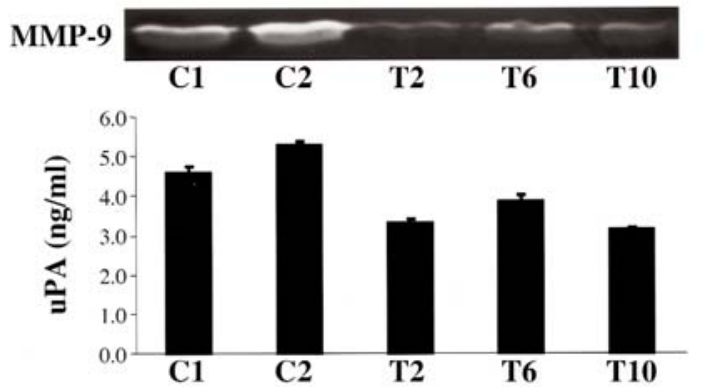

Figure 4. Effect of TSP-2 expression on cellular invasiveness, MMP-9 and uPA activities in PANC-1 cells. (A) Invasion was assayed in BD BioCoat ${ }^{\mathrm{TM}}$ Matrigel $^{\mathrm{TM}}$ Invasion Chambers. Cellular invasiveness was normalized to the number of each type of cells that had migrated through the Matrigel. This revealed significant differences between PANC-C and - T cells ( $\mathrm{p}<0.05$ in T2, T6 and T10; Welch test). (B) The expression of MMP-9 in conditioned media was analyzed by gelatin zymography. MMP-9 showed significantly lower activity in the conditioned media of PANC-T than -C clones. (C) uPA concentration in the conditioned media of PANC-C and - $\mathrm{T}$ clones was measured using a total uPA ELISA Kit. Concentrations were: C1, $4.57 \pm 0.18 \mathrm{ng} / \mathrm{ml}$; 2 , $5.27 \pm 0.1 ; \mathrm{T} 2,3.30 \pm 0.1 ; \mathrm{T} 6,3.83 \pm 0.17 ; \mathrm{T} 10,3.14 \pm 0.57$. T2 and $\mathrm{T} 10$ showed significantly lower levels of uPA than the control cells ( $\mathrm{p}<0.05$; Welch test).

vector-transfectants $\left(\mathrm{C} 1,0.12 \times 10^{-4} \pm 0.34 ; \mathrm{C} 2,0.52 \times 10^{-5} \pm 0.0\right)$ (Fig. 3A). Western blot analysis confirmed the increased protein levels of TSP-2 in TSP-2-transfectants (Fig. 3B).

Effect of TSP-2 expression on the cellular invasiveness of PANC-1 cells. To investigate the invasion ability of PANC-1 cells to overexpress TSP-2 (PANC-T), Matrigel ${ }^{\mathrm{TM}}$ Invasion Assays were performed (Fig. 4A). The propensity of cells to penetrate through basement membrane-simulating Matrigel was used as an index of cellular invasive potential. The cel- 
lular invasiveness of each type of cell was as follows: C1, $0.52 \pm 0.07 \% ; \mathrm{C} 2,0.57 \pm 0.02 \% ; \mathrm{T} 2,0.13 \pm 0.02 \%$; T6, $0.07 \pm 0.001 \%$; T10, $0.11 \pm 0.01 \%$. These results reveal the significant suppression of the invasiveness of the pancreatic cancer cell lines expressing TSP-2 in comparison with PANC-C $(\mathrm{p}<0.05$ in T2, T6 and T10; Welch test).

Effect of TSP-2 expression on MMP-9 and UPA activity in PANC-1 cells. To assess the effects of TSP-2 on pancreatic cancer cell invasiveness, we first determined MMP-9 activity in PANC-T cells. Gelatin-zymography analysis of MMP-9 in the conditioned media of PANC-T clones showed significantly lower activity than in the media of PANC-C clones (Fig. 4B). Because uPA is also known to be involved in the breakdown of the extracellular matrix, resulting in tumor cell invasion, we then examined the total amount of uPA in the conditioned media by ELISA. The concentrations were as follows: $\mathrm{C} 1$, $4.57 \pm 0.18 \mathrm{ng} / \mathrm{ml} ; \mathrm{C} 2,5.27 \pm 0.1$; T2 , 3.30 \pm 0.1 ; T6, 3.83 \pm 0.17 $\mathrm{T} 10,3.14 \pm 0.57$. T2 and T10 showed significantly lower levels of uPA in the medium ( $\mathrm{p}<0.05$; Welch test) (Fig. 4C).

\section{Discussion}

In the present study, we examined the biological roles of TSP-2 in human PANC-1 pancreatic cancer cells. We isolated three clones of PANC-1 transformants stably overexpressing human TSP-2 (PANC-T). The invasiveness of the PANC-T clones was significantly suppressed in in vitro invasion assays. The restoration of TSP-2 synthesis significantly inhibited MMP-9 and uPA activity in the PANC-T clones. These results suggest that restoration of TSP-2 can inhibit cell invasion through the down-regulation of MMP-9 and uPA activity in pancreatic cancer.

The effect of TSP-2 on the metastasis of pancreatic cancer cells is not known in detail, while the biological function of tumor cell-produced TSP-1 has provided evidence supporting its role in tumor progression. To determine the role of TSP-2 in pancreatic cancer tumor progression, we established PANC-1 transformants which stably overexpressed TSP-2. TSP-1 expression was observed in neither the control nor TSP-2transfected cells. The process by which epithelial cancer cells metastasize is hypothesized to consist of a series of linked sequential steps, the most critical of these being cellular invasion through the basement membrane. Our findings indicate that the cellular invasiveness of TSP-2-overexpressing tumor cells was obviously decreased. This suggests that secreted TSP-2 might affect tumor cells, inhibiting their invasion.

As a possible mechanism underlining the difference in tumor invasiveness, we focused on the role of MMPs (15). MMPs and matrix serine proteases are known to be major groups of secretory proteinases that play essential roles in various physiological and pathological processes, including tumor invasion and metastasis. The proteolytic plasminogen activation system plays an important role in the invasion and metastasis of pancreatic cancer (24). Two functionally and structurally different PAs, uPA and tPA, are both capable not only of catalyzing the conversion of the inactive zymogene plasminogen to the active proteinase plasmin, but also of degrading extracellular matrix macromolecules. Moreover, uPA is a potent activator of many latent MMPs, and in general the activities of MMPs and UPA are known to parallel the potential for tumor invasion and metastasis (25-27). In our previous study, TSP-2-transfected colon cancer cells showed decreased expression of MMP-2 and -9 mRNA in comparison to the control cells (17), and TSP-2 protein was shown to be involved in the regulation of metalloproteinase activity by inhibiting zymogen activation (28). In this study, our results demonstrate that MMP-9 activity is significantly suppressed in TSP-2-overexpressing PANC-1 cells. This suggests the possibility of a close relationship between TSP-2 and the modulation of MMP-9 and uPA. Regarding their inhibitor, we have also reported that TSP-2-transfected SW480 cells exhibit preservation of the expression of TIMP-1 to -3 mRNA (17).

TSP-1 and -2 have a high degree of sequence homology; however, they differ significantly in the amino-terminal heparin-binding domain (3-5). As the tissue-specific and developmental patterns of the thrombospondins differ, expression of these gene products is likely to be subject to different regulatory controls. TSP-1 expression in pancreatic cancer cells has been demonstrated in previous studies. Qian et al (29) reported that $85 \%$ of cases of pancreatic adenocarcinomas exhibited high expression of TSP-1 by immunostaining. Meanwhile, the expression pattern and significance of TSP-2 in pancreatic cancer is not known. In this study, three of the four pancreatic cancer cell lines examined exhibited significant TSP-1 expression, while none showed expression of TSP-2. We confirmed the constitutive gene expression of TSP-1 and -2 in four pancreatic cancer cell lines.

In conclusion, our results suggest that TSP-2 acts as a potent inhibitor of tumor cell invasion through the modulation of MMPs in pancreatic cancer. The potential usefulness of TSP-2 as a therapeutic agent for pancreatic cancer warrants further investigation.

\section{Acknowledgements}

We are grateful to Dr Johbu Itoh and Mr. Yuichi Tada at the Department of Pathology, Tokai University, for their technical assistance and helpful discussions.

\section{References}

1. Murr MM, Sarr MG, Oishi AJ and van Heerden JA: Pancreatic cancer. CA Cancer J Clin 44: 304-318, 1994.

2. Iwamura T, Katuski T and Ide K: Establishment and characterization of a human pancreatic cacer cell line (SUIT-2) producing carcinoembryonic antigen and carbohydrate antigen 19-9. Jpn J Cancer Res 78: 54-62, 1987.

3. Volpert OV, Tolsma SS, Pellerin S, Feige JJ, Chen H, Mosher DF and Bouck N: Inhibition of angiogenesis by thrombospondin-2. Biochem Biophys Res Commun 217: 326-332, 1995.

4. Streit M, Riccardi L, Velasco P, Brown LF, Hawighorst T, Bornstein P and Detmar M: Thrombospondin-2: a potent endogenous inhibitor of tumor growth and angiogenesis. Proc Natl Acad Sci USA 96: 14888-14893, 1999.

5. Kyriakides TR, Zhu YH, Yang Z and Bornstein P: The distribution of the matricellular protein thrombospondin 2 in tissues of embryonic and adult mice. J Histochem Cytochem 46: 1007-1015, 1998.

6. Iruela-Arispe ML, Bornstein P and Sage H: Thrombospondin exerts an antiangiogenic effect on cord formation by endothelial cells in vitro. Proc Natl Acad Sci USA 88: 5026-5030, 1991.

7. Weinstat-Saslow DL, Zabrenetzky VS, van Houtte K, Frazier WA, Roberts DD and Steeg PS: Transfection of thrombospondin 1 complementary DNA into a human breast carcinoma cell line reduces primary tumor growth, metastatic potential, and angiogenesis. Cancer Res 54: 6504-6511, 1994. 
8. Good DJ, Polverini PJ, Rastinejad F, Le Beau MM, Lemons RS, Frazier WA and Bouck NP: A tumor suppressor-dependent inhibitor of angiogenesis is immunologically and functionally indistinguishable from a fragment of thrombospondin. Proc Natl Acad Sci USA 87: 6624-6628, 1990.

9. Lawler J: The functions of thrombospondin-1 and -2. Curr Opin Cell Biol 12: 634-640, 2000.

10. Folkman J: Angiogenesis in cancer, vascular, rheumatoid and other disease. Nat Med 1: 27-31, 1995.

11. Tolsma SS, Volpert OV, Good DJ, Frazier WA, Polverini PJ and Bouck N: Peptides derived from two separate domains of the matrix protein thrombospondin-1 have anti-angiogenic activity. J Cell Biol 122: 497-511, 1993.

12. Bornstein P: Diversity of function is inherent in matricellular proteins: an appraisal of thrombospondin 1. J Cell Biol 130: 503-506, 1995.

13. Streit M, Velasco P, Brown LF, Skobe M, Richard L, Riccardi L, Lawler J and Detmar M: Overexpression of thrombospondin-1 decreases angiogenesis and inhibits the growth of human cutaneous squamous cell carcinomas. Am J Pathol 155: 441-452, 1999.

14. Rofstad EK and Graff BA: Thrombospondin-1-mediated metastasis suppression by the primary tumor in human melanoma xenografts. J Invest Dermatol 117: 1042-1049, 2001.

15. Liotta LA: Tumor invasion and metastasis - role of the extracellular matrix: Rhoads Memorial Award lecture. Cancer Res 46: $1-7,1986$.

16. Murphy $\mathrm{G}$ and Garantilovic J: Proteolysis and cell migration: creating a path? Curr Opin Cell Biol 11: 614-621, 1999.

17. Kamochi J, Tokunaga T, Tomii Y, Abe Y, Hatanaka H, Kijima H, Yamazaki H, Watanabe N, Matsuzaki S, Ueyama Y and Nakamura M: Overexpression of the thrombospondin 2 (TSP2) gene modulated by the matrix metalloproteinase family expression and production in human colon carcinoma cell line. Oncol Rep 10: 881-884, 2003.

18. Tomii Y, Kamochi J, Yamazaki H, Sawa N, Tokunaga T, Ohnishi Y, Kijima H, Ueyama Y, Tamaoki N and Nakamura M: Human thrombospondin 2 inhibits proliferation of microvascular endothelial cells. Int J Oncol 20: 339-342, 2002.

19. Abe Y, Nakamura M, Ohnishi Y, Inaba M, Ueyama Y and Tamaoki N: Multidrug resistance gene (MDR1) expression in human tumor xenografts. Int J Oncol 5: 1285-1292, 1994
20. Abe Y, Ohnishi Y, Yoshimura M, Ota E, Ozeki Y, Oshika Y, Tokunaga T, Yamazaki H, Ueyema Y, Ogata T, Tamaoki N and Nakamura M: P-glycoprotein-mediated acquired multidrug resistance of human lung cancer cells in vivo. Br J Cancer 74: 1929-1934, 1996.

21. Hamamoto A, Abe Y, Nishi M, Fujimori S, Ohnishi Y, Yamazaki H, Oida Y, Miyazaki N, Inada K, Ueyama Y, Iwasaki $\mathrm{M}$, Inoue $\mathrm{H}$ and Nakamura $\mathrm{M}$ : Aberrant expression of the gastric mucin MUC6 in human pulmonary adenocarcinoma xenografts. Int J Oncol 26: 891-896, 2005.

22. Oida Y, Gopalan B, Miyahara R, Inoue S, Branch CD, Mhashilkar AM, Lin E, Beckele BN, Roth JA, Chada S and Ramesh R: Sulindac enhances adenoviral transfer expressing mda7/IL-24-mediated apoptosis in human lung cancer. Mol Cancer Ther 4: 291-304, 2005.

23. Hanzawa M, Shindoh M, Higashino F, Yasuda M, Inoue N, Hida K, Ono M, Kohgo T, Nakamura M, Notani K, Fukuda H, Totsuka Y, Yoshida K and Fujinaga K: Hepatocyte growth factor upregulates E1 AF that induces oral squamous cell carcinoma cell invasion by activating matrix metalloproteinase genes. Carcinogenesis 21: 1079-1085, 2000.

24. Andreasen PA, Egelund R and Petersen HH: The plasminogen activation system in tumor growth, invasion, and metastasis. Cell Mol Life Sci 57: 25-40, 2000.

25. Neurath H: Evolution of proteolytic enzymes. Science 224: 350-357, 1984.

26. Mignatti $P$ and Rifkin DB: Biology and biochemistry of proteinases in tumor invasion. Physiol Rev 73: 161-195, 1993.

27. Nelson AR, Fin gleton B, Rothenberg ML and Matrisian LM Matrix metalloproteinases: biologic activity and clinical implications. J Clin Oncol 18: 1135-1149, 2000.

28. Bein K and Simons M: Thrombospondin type 1 repeats interact with matrix metalloproteinase 2. Regulation of metalloproteinase activity. J Biol Chem 275: 32167-32173, 2000.

29. Qian X, Rothman VL, Nicosia RF and Tuszynski GP: Expression of thrombospondin-1 in human pancreatic adenocarcinomas: role in matrix metalloproteinase-9 production. Pathol Oncol Res 7: 251-259, 2001. 